\begin{tabular}{|c|c|c|c|c|c|c|}
\hline \multicolumn{7}{|c|}{ Demographic, clintcal ond serological charactersittcs of pattents $(n=68)$} \\
\hline \multicolumn{2}{|c|}{$\begin{array}{c}\text { Female } \\
\mathbf{n}(\%)\end{array}$} & \multicolumn{5}{|c|}{$54(79,4 \%)$} \\
\hline \multicolumn{2}{|c|}{ Age ( \pm d.s.) } & \multicolumn{5}{|c|}{28 ami $( \pm 10)$} \\
\hline \multicolumn{2}{|c|}{$\begin{array}{l}\text { Disease duration } \\
\text { ( } \pm \text { d.s.) }\end{array}$} & \multicolumn{5}{|c|}{17 anni $( \pm 10)$} \\
\hline \multicolumn{2}{|c|}{ Uveitis } & \multicolumn{5}{|c|}{$12(17,6 \%)$} \\
\hline \multirow{2}{*}{$\begin{array}{l}\text { Diagnostic } \\
\text { suggroups }\end{array}$} & \multirow{2}{*}{$\begin{array}{c}\text { Sistemic } \\
\text { JA } \\
\mathrm{n}=10 \\
(14,7 \%)\end{array}$} & \multirow{2}{*}{$\begin{array}{c}\text { Oligoarticular JIA } \\
\quad \mathrm{n}=28(41,2 \%)\end{array}$} & \multicolumn{2}{|c|}{$\begin{array}{c}\text { Poliarticular JIA } \\
\quad \mathrm{n}=20(29,4 \%)\end{array}$} & \multirow{2}{*}{$\begin{array}{c}\text { Psoriasic } \\
\text { JA } \\
\text { n=3 } \\
(4,4 \%)\end{array}$} & \multirow{2}{*}{$\begin{array}{c}\text { Entesitic } \\
\text { JA } \\
\mathbf{n}=7 \\
(10,3 \%)\end{array}$} \\
\hline & & & $\begin{array}{c}\mathbf{R F} \\
\text { Positiv } \\
\mathbf{n}=9\end{array}$ & $\begin{array}{c}\mathbf{R F} \\
\text { Negativ } \\
\mathrm{n}=11\end{array}$ & & \\
\hline $\begin{array}{r}\text { Female } \\
\mathrm{n}(\%)\end{array}$ & $6(60 \%)$ & $13(46.4 \%)$ & $9(100 \%)$ & $9(\$ 1 \%)$ & $2(67 \%)$ & $2(28,5 \%)$ \\
\hline Uveitis & 0 & $8(28,6 \%)$ & 0 & $2(18 \%)$ & 0 & $2(28,5 \%)$ \\
\hline
\end{tabular}
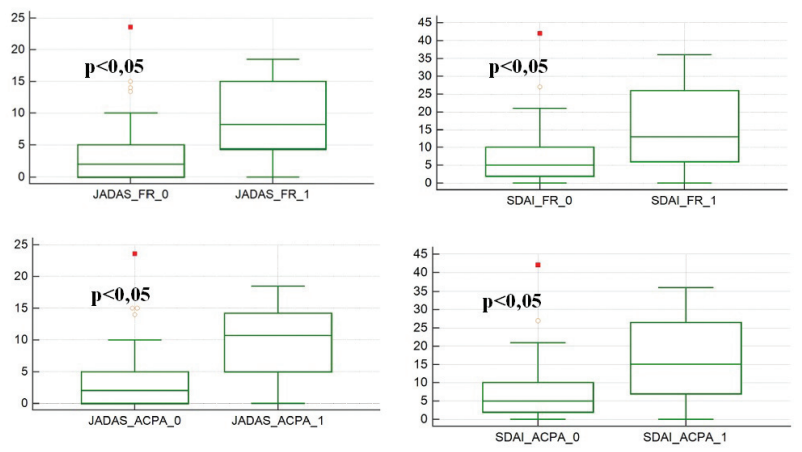

Figure 1

Disclosure of Interests: Marta Priora Grant/research support from: Sanofi SpA, Tilde Manetta: None declared, Simone Parisi Speakers bureau: Chiesi, Jansenn, Pfizer, Celgene, Abbvie, Lilly., Maria Chiara Ditto: None declared, Silvia Sanna Grant/research support from: Novartis, Richard Borrelli: None declared, Enrico Fusaro Grant/research support from: Abbvie

Abiogen

Actelion

Amgen

Biogen

BMS

Celgene

Grunenthal

GSK

Janssen

Lilly

MSD

Mundipharma

Novartis

Pfizer

Roche

SANOFI

SOBI

UCB

DOI: 10.1136/annrheumdis-2019-eular.1566

\section{AB1038 JUVENILE IDIOPATHIC ARTHRITIS INTO ADULTHOOD: HOW DO WE ASSESS DISEASE ACTIVITY?}

Marta Priora, Clara Lisa Peroni, Angela Laganà, Richard Borrelli, Enrico Fusaro. A O.U. Città della Salute e della Scienza, Rheumatology, Turin, Italy

Background: Deepening the long-term study of Juvenile Idiopathic Arthritis (JIA) in adulthood is essential to increase the pathogenetic knowledge of the disease, to optimize the therapeutic choices accordingly, as well as to promote a more active communication between paediatric care and adult care specialists

Objectives: The present project, created as part of the "transition of care", aims to compare clinimetric scores of wide use for adult inflammatory rheumatisms of the adult (DAS28, CDAl and SDAI) with the JADAS27 score, which has been validated and widely used in order to quantify JIA's activities in the paediatric field. As of today, adult patients with JIA are usually evaluated with clinimetric scores developed for adult chronic rheumatic diseases (DAS28, CDAI, SDAI) and there is no consensus concerning which of these scores doctors should favour, so that the choice is quite autonomous and varies from centre to centre. It is therefore of interest to verify whether among these indices of purely rheumatological use of adults there is one that is more appropriate than JADAS27 which can be useful in monitoring adult patients with JIA.

Methods: The relevant clinical data were collected from 68 adult patients with JIA. A correlation analysis was performed between the clinimetric scores according to McNemar Test and Kappa by Cohen.

Results: The results obtained suggest that none of the clinimetric scale commonly used in the rheumatological clinical practice of adult patients can completely replace JADAS27. DAS28 is the score that goes further from an acceptable correlation with JADAS. Since both CDAI and SDA are calculated with formulas that are similar to the one used for JADAS (algebraic sums of affected joints, subjective outcomes reported by the patient, clinical judgment of the physician), they happen to be a method of quantification of disease activity quite closer to JADAS itself. The analyses outlined a scenario in which a much larger portion of patients are classified in remission stages or in low disease activity when using CDAl and SDAI compared to JADAS27.
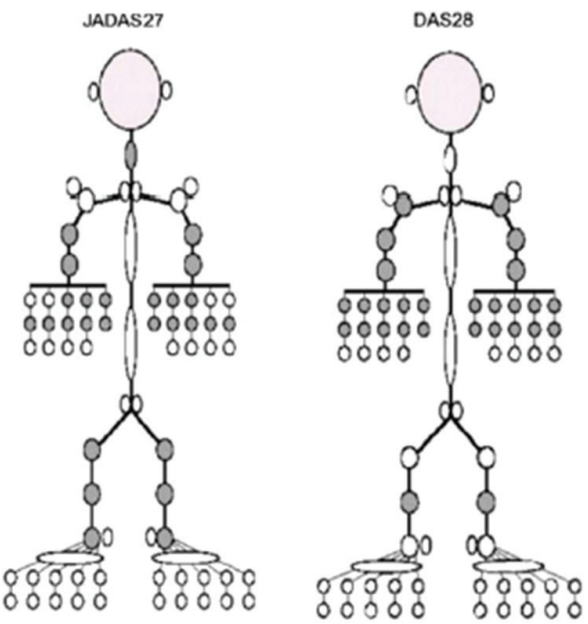

\begin{tabular}{|l|c|c|}
\hline & Test di McNemar & Kappa di Cohen \\
\hline JADAS-DAS28 & $\mathrm{p}=0, \mathbf{0 0}$ & $\mathbf{0 , 0 8}$ \\
\hline JADAS-CDAI & $\mathrm{p}=0, \mathbf{0 0}$ & 0,11 \\
\hline JADAS-SDAI & $\mathrm{p}=0,00$ & $\mathbf{0 , 2 0}$ \\
\hline
\end{tabular}

Figure 1

Conclusion: This element inspired us to consider how in paediatric age a more "demanding" attitude towards the disease led to the validation of both a score and its very stringent cut-offs which are functional to a treat to target characterized by a complete remission whose main goal is to avoid long-term sequelae. SDAl was found to be the scale of common use in the adult care that more properly approaches the clinometry validated for the paediatric population (JADAS27). Although clinical common sense should not distract from assessing disease activity in this specific patient population from a global perspective, such a study could suggest using SDAI as clinimetric score of choice in adult patients with JIA. Further checks in larger population samples are obviously necessary.

\section{REFERENCES}

[1] Oliveira-Ramos F, Eusébio M, et al. Juvenile idiopathic arthritis in adulthood: fulfilment of classification criteria for adult rheumatic diseases, longterm outcomes and predictors of inactive disease, functional status and damage. RMD Open.2016; (2)

[2] Coulson EJ, Hanson HJM, et al. What does an adult rheumatologist need to know about juvenile idiopathic arthritis? Rheumatology. 2014;53(12).

[3] Selvaag AM, Aulie HA, et al. Disease progression into adulthood and predictors of long-term active disease in juvenile idiopathic arthritis. Ann Rheum Dis. 2016;75(1)

Disclosure of Interests: Marta Priora Grant/research support from: Sanofi SpA, Clara Lisa Peroni: None declared, Angela Laganà: None declared Richard Borrelli: None declared, Enrico Fusaro Grant/research support from: Abbvie

Abiogen 
Actelion

Amgen

Biogen

BMS

Celgene

Grunenthal

GSK

Janssen

Lilly

MSD

Mundipharma

Novartis

Pfizer

Roche

SANOFI

SOBI

UCB

DOI: 10.1136/annrheumdis-2019-eular.1711

\section{AB1039 ADA2 DEFICIENCY PRESENTING AS INFANTILE POLYARTERITIS NODOSA}

Graça Loureiro $^{1}$, Diana Oliveira ${ }^{2}$, Sara Ganhão ${ }^{3}$, Francisca Aguiar ${ }^{3}$, Mariana Rodrigues ${ }^{3}$, Iva Brito ${ }^{3}{ }^{1}$ Centro Hospitalar de Entre Douro e Vouga, Paediatrics, Santa Maria da Feira, Portugal; ${ }^{2}$ Hospital de Braga, Paediatrics, Braga, Portugal, 3Hospital São João, Porto, Portugal

Background: Polyarteritis nodosa (PAN) is a rare form of primary systemic vasculitis with heterogeneous presentations, treatments and disease course. There have been improvements in understanding of certain causes of PAN such as the association of the monogenic disorder Deficiency of Adenosine Deaminase 2 (DADA2) with a PAN phenotype. This described autoinflammatory disease is caused by loss-of-function homozygous or compound heterozygous mutations in CECR1 and can be characterised by an early onset vasculopathy with clinical and histopathological features of PAN associated with haemorrhagic and ischaemic strokes.

Objectives: We report a case of a 14 year-old boy, with a prenatal diagnosis of Klinefelter syndrome, whose parents are first cousins.

Methods: Review of patient's clinical records and scientific literature.

Results: During his first two years of age, he suffered two small strokes, was investigated in another Hospital and no diagnosis was made. At 4 years of age he was admitted to another hospital for prolonged fever and arthralgia. At age 5 he was admitted to our hospital for fever, arthralgia and myalgia. He later developed a medular stroke and arterial hypertension. Due to suspected PAN he underwent a renal angiogram which confirmed our suspicion.

He completed induction treatment with IV cyclophosphamide (6 months), steroids, acetylsalicylic acid (ASA), warfarin and ramipril, followed by maintenance with azathioprine (AZA)

While on remission, 2 weeks after after stopping warfarine he suffered a transient ischemic attack; brain-MRI showed a small de novo thalamic lesion.

CECR1 testing revealed c. $1226 \mathrm{C}>\mathrm{A}$ variant in homozygosity, his parents are both carriers. ADA2 enzymatic activity was then tested and was absent, which confirms the diagnosis. IgM levels are low. He started adalimumab and stopped warfarin, aspirin and AZA. He mantains follow-up, with no sequelae to his strokes and apparent clinical remission.

Conclusion: The age of onset and clinical manifestations of DADA2 vary widely and are not clearly related to the genotype. Although this variant in CECR1 was of uncertain pathological significance, the absence of ADA2 enzymatic activity confirms the diagnosis.

Timely diagnosis and treatment with anti-TNF drugs are thought to be crucial to prevent severe complications. Also, these patients should not be treated with ASA or anticoagulants which are frequently used in PAN patients. Low IgM levels can be a clue to raise the suspicion.

Lack of long term outcome data in children with DADA2 makes the prognosis uncertain and underlines the need to maintain a lifelong follow-up.

\section{REFERENCES}

[1] Zhou $Q$ et al. Early-onset stroke and vasculopathy associated with mutations in ADA2. N Engl J Med. 2014 Mar 6;370(10):911-20

[2] Navon $\mathrm{E}$ et al. Mutant adenosine deaminase 2 in a polyarteritis nodosa vasculopathy. N Engl J Med. 2014 Mar 6;370(10):921-31.
Acknowledgement: The authors wish to thank Gustavo M Santo for his cooperation.

Disclosure of Interests: None declared

DOI: 10.1136/annrheumdis-2019-eular.7627

\section{AB1040 PEDIATRIC SJÖGREN SYNDROME: A MONOCENTER CASE SERIES}

micol romano ${ }^{1}$, Gabriella Maioli ${ }^{1}$, Angela Flavia Luppino ${ }^{1}$, Maurizio Gattinara ${ }^{1}$, Valeria Gerloni ${ }^{2} .{ }^{1}$ ASST Pini-CTO - Presidio Gaetano Pini, University of Milan, Pediatric Rheumatology, Milano, Italy, ${ }^{2}$ Casa di Cura La Madonnina, Milan, Milano, Italy

Background: Sjögren syndrome (SS) is a chronic autoimmune disorder characterized by inflammation of the lacrimal and salivary glands leading to oral and ocular dryness. Childhood SS is rare and poorly defined and underdiagnosed owing to the lack of child-specific diagnostic or classification criteria [1].

Objectives: The purpose of this study is to describe five cases with pediatric SS in order to better clarify the characteristics of the disease in the childhood.

Methods: We retrospectively reviewed medical records of patients with pediatric SS referring to our center (ASST-PINI-CTO, University of Milan) from November 2008 to December 2018. No adequate childhood SS-specific criteria exist. Therefore we select our pts according to a combination of clinical, serological, histopatological findings. For the assessment of systemic disease activity we applied ESSDAI (EULAR Sjögren's syndrome disease activity index). We calculated ESSDAI at diagnosis, at the peak disease activity and at the last follow up visit.

Results: We collected data on 5 pts ( 4 females). The mean of age at onset is $8.4 \mathrm{yrs}$ (range 4.8-11.2). The mean of age at diagnosis is 10.8 (range 6.5-13.3). The follow up period varied from 1.2 to $9.3 \mathrm{yrs}$ (mean 6.3). The most common manifestations were parotid/salivary glands swelling (5/5 pts) and articular involvement (5/5 pts) with arthritis in 2 pts and arthralgia in the others. Nobody of our pts presented dryness of eyes. Xerostomia was found in $2 / 5$ pts. Fever and fatigue occurred in 2/ 5 and $3 / 5$ pts respectively. We also recorded 2 cases of abdominal pain, 1 case of glomerular proteinuria, 2 cases of purpura and 1 case of erythema nodosum. ANA, anti-SSA, anti-SSB, RF, elevation of ERS and hypergammaglobulinemia $(1.6-8.04 \mathrm{~g} / \mathrm{dl})$ were present in all cases. Minor salivary gland biopsy was performed in 4 pts resulting in histological evidence of focal lymphocytic sialadenitis (one of them showed chronic sialadenitis with a focus score $<1 / 4 \mathrm{~mm} 2$ ). Ultrasound studies of salivary glands were positive in $5 / 5$ cases. Mean ESSDAI scores at diagnosis, peak activity and the last follow up visit were 8 (range 5-11), 13.2 $(9-20), 4.8(0-9)$. The most frequently involved domains at the peak activity were biological (5/5), parotid/salivary glands swelling (5/5) and articular $(5 / 5)$. No major complications have been observed. With regard to treatment, all patient received corticosteroids and DMARDs (5/5 hydroxychloroquine, 3/5 methotrexate, 1/5 azathioprine, 1/5 leflunomide); one patient needed plasmapheresis and immunosuppressive therapy with cyclophosphamide. Biological therapy was administered to 2 patients: 1 received belimumab and then rituximab, while the other patient received rituximab. Conclusion: Xerostomia and keratoconjunctivitis sicca are not a common features in children, on the other hand juvenile SS has higher incidence of recurrent parotid swellings than adults [2, 3]. All pts had laboratory abnormalities. The long-term prognosis of pediatric SS is unknown, in ou series only 2 patients were inactive (ESSDAI score $<5$, according to the definition by EULAR) at last evaluation, 3 were moderately active with a minimal clinically important improvement (MCII) observed in all of them [4].

\section{REFERENCES}

[1] Lieberman SM. Curr Opin Rheumatol, 2013.

[2] Kobayashi I et al, Modern Rheumatology, 2018.

[3] Cimaz R et al, Eur J Pediatr, 2003

[4] Seror R et al, RMD Open, 2015.

Disclosure of Interests: None declared DOI: 10.1136/annrheumdis-2019-eular.5773 